\title{
Research on Implementing ERP in a Northeastern Enterprise Based on Information Orientation Theory
}

\author{
Lei Ye and Yuqiang Feng \\ School of Management, Harbin Institute of Technology, Harbin 150001, Heilongjian, P.R. \\ China mis_yelei@126.com fengyq@hit.edu.cn
}

\begin{abstract}
Based on information orientation theory, the entire process of ERP implementation in enterprise is analyzed in detail from information behaviors and values, information management practice, and information technology practice. Advantages and disadvantages are both listed to show the benefits or barriers to the implementing of ERP in northeastern enterprises. After the analysis of an empirical ERP implementation of a northeastern pharmacy group, suggestions and problems that need to be awared in ERP implementation of northeastern enterprises are given.
\end{abstract}

Keywords: Information orientation theory, ERP, Implementation, Northeastern enterprise, Regional specificities

\section{INTRODUCTION}

ERP was suggested as a managerial tool for enterprise to govern all related resources inside and outside of enterprise to ensure sustainable competitive advantages. Most of ERP researches concern mainly on implementation methods or factors that lead to successful implementation. By constructing new evaluation frameworks for ERP implementation effectives, some researchers justified their work through sample enterprises. Others' work consider about methodologies that start from requirement analysis to technical support after implementation. Though all resources inside of enterprise are coded as digital information in kinds of management software, it's rarely to see researches about how information are located, and managed in ERP, needless to say researches about using and creating of information.

Information system research has long been developed mainly from two approaches--user satisfaction [1] and technology acceptance [2]. Both of the two approaches take the influence of information as a mediator. Researches from user satisfaction field point out that users' evaluation about information has a great influence to user satisfaction which contains completeness, accuracy, and format of information [3]. On the other hand, Davis, one of the pioneers in technology acceptance research, suggested information quality in his TAM2 model. However, there are little researches or theories take information as a determinant, not to say as a target. That's the reason we consider Information Oriented Theory as our research tool.

Please use the following format when citing this chapter

Ye, L., Feng. Y., 2007, in IFIP International lederation for Information Processing. Volume 254. Research and Practical Issues of Enterprise Information Systems II Volume 1, eds. L. Xu. Tjoa A.. Chaudhry S. (Boston: Springer), pp. 251256 . 
Information orientation theory was first brought up by Marchand [4]. Marchand figured that a successful and effective use of information technologies was composed by three parts: information technology practice, information manage practice, and information behaviors \&values, and company must achieve competence and synergy across all these capabilities of effective information use as a precondition to achieve superior business performance" [5-6].In his articles, Marchand pointed out that information's value are greatly underestimated in enterprise. The consideration of information as a container instead of a target lead to greatly information redundancy or information waste which aggravate the burden of information system.

How to consider information during ERP project implementation is a question that needs to focus on. Project managers, either from enterprise or implementation party, take project completion in time as their final goal. All they care about are functions in ERP system, and sometimes about the precise of data, but seldom if any about the usage or reuse of information, which leads to great loss for enterprise after implementation party leaves. Based on information orientation theory, we suggest that both of implementation party and client party should integrate the three capabilities about information during their implementation process. Our research is done during an ERP implementation process of a certain northeastern enterprise. Notification and suggestions about how to integrate are given and discussed.

\section{INFORMATION TECHNOLOGY PRACTICE (ITP) AND RELATED IMPLEMENTATION MEASURES}

ITP includes four parts: IT managerial support, IT business process support, IT operational support and IT innovation support. All these four parts are related more to software foundations rather than human resource or organization structure.

IT managerial support refers to IT technologies that assist managers to make decisions. After being processed completely, information flows to this module. Managers then can use them to make decisions. Nowadays, many ERP software suppliers afford data analyzing modules in their products to complete this task.

IT business process support aims at optimizing the business process. Information can flow much more rapidly and effectively through organized and efficient process. Valuable information comes from both inside and outside, like from supply chain or demand chain. While doing ERP implementation, consultants usually make adjustments to business process in order to make system works efficiently.

IT operation support deals with specific business matters including accounting, manufacturing, sale and etc. With these steps of operation, Lot of information is generated or collected. Matters that influence the operation support include system function, training, hardware configuration and etc.

IT innovation support is mainly discussed in R\&D departments which are responsible for new products/services, and creativity-exploration improving. Information system relates to IT innovation support refers to Groupware, CAX, Enterprise Knowledge Portals and so on. As ERP system is concerned, it should consider appropriate integration with those specific systems.

Table 1 concludes related ERP behaviors to ITP mentioned above. Compared to capabilities, ITP is the least underestimated part during implementation. 
Table 4. Related ERP Behaviors to ITP

\begin{tabular}{|c|c|c|c|}
\hline & ITP Support & $\begin{array}{l}\text { Types of knowledge } \\
\text { workers }\end{array}$ & $\begin{array}{l}\text { ERP } \\
\text { assistance/related }\end{array}$ \\
\hline \multirow{2}{*}{$\begin{array}{l}\text { Making } \\
\text { better } \\
\text { things }\end{array}$} & $\begin{array}{l}\text { ITP of } \\
\text { management }\end{array}$ & $\begin{array}{l}\text { Executives/senior } \\
\text { managers }\end{array}$ & $\begin{array}{ll}\text { Data analyzing } \\
\text { modules }\end{array}$ \\
\hline & $\begin{array}{l}\text { ITP of } \\
\text { innovation }\end{array}$ & R\&D workers & $\begin{array}{l}\text { Integration with } \\
\text { other systems }\end{array}$ \\
\hline \multirow{2}{*}{$\begin{array}{l}\text { Making } \\
\text { things } \\
\text { better }\end{array}$} & ITP of BP & Process managers & BPR \\
\hline & $\begin{array}{l}\text { ITP of } \\
\text { operation }\end{array}$ & $\begin{array}{l}\text { Operational workers } \\
\text { supervisors }\end{array}$ & Modules, training. \\
\hline
\end{tabular}

\section{INFORMATION MANAGEMENT PRACTICE (IMP) AND RELATED IMPLEMENTATION MEASURES}

IMP is a process that neglected by project managers. It manages information effectively over the life cycle of information use including sensing, collecting, organizing, processing, and maintaining information [6].

Information sensing is essential to high level of IMP maturity as companies must continuously identify events, trends and changes in business conditions and make sense out of them to collect appropriate information, develop new strategies, or make decisions [6]. Information movement is the usage process of information, while sensing is the start of information movement. ERP system do not usually automatically contain module that realizing such function, but do afford interface to input them. Take purchase price as an example. After sensing material price, clerks in purchase department are required to collect and key in them into ERP system. In other words, information's sensing and collecting are done simultaneously.

After information sensing and collecting, much information in system should be organized next. Due to different macro factors like economy environment, characters of industry, content of fierce competition, and micro factors like enterprise's purpose, availability of human resource etc., different enterprises have different classification. That's the reason why classification of information organization is different in different enterprise. According to Marchand, information organizing depends on collecting phase and on good IT supports [6].

Besides information sensing, information processing is one of the most critical aspects of IMP. Marchand deems information processing including evaluation of information's relevance and importance to decide whether maintain for the future use or not. However, that's not the only reason for enterprise to evaluate and process information in our case of ERP implementation. Information processing is also responsible for valuable operational information, such as Return of Investment (ROI) calculation. Many ERP systems afford module to generate such kind of indirect information by processing raw information.

Maintaining is the last step for IMP. After processing, information is maintained for reusing and refreshing to avoid expensive and time-consuming double collection 
[7]. Maintaining implies a thing that manager level should decide which information is valuable enough to be maintained. The process of decision is a clarification of enterprise's core competencies. Users can take advantages of various rules in ERP system to filter and maintain required information.

\section{INFORMATION BEHAVIORS AND VALUES (IBV) AND RELATED IMPLEMENTATION MEASURES}

IMP depicts the flow movement of information while IBV describes movement of human being involved with information. Marchand deems there are six IBV capabilities: proactiveness, sharing, transparency, control, formality, and integrity.

Specifically speaking, integrity aims at defining the type of information by their privacy in order to protect confidential information. We view integration as an efficient way to eliminate noises and useless information or redundant one. There is much information in enterprise especially for manufacturing industry. Much of them overlap. For example, storage department is usually responsible for the delivery statistics, while logistics does the same thing too. ERP system can decrease such phenomena by integrating information.

Formality is the necessary process for following steps. Information from different origins differs in coding, meaning and many other ways. Hasty using without preprocess leads to misunderstanding and mistakes. Unification through information transforming is the premise for maximal and reasonable use of information.

Information control indicates the information using circumstance by employees from all levels of enterprise. It mainly controls the flow direction of information. Business process reengineering is one of the important ways that influences information controls by change its direction.

Transparency, sharing and proactiveness are considerations about information openness. While in our research, as ERP system is concerned, information openness is inhibited by rules in enterprise and controlled by system modules. Table 2 concludes related ERP behaviors to IMP and IBV mentioned above.

\section{CASE STUDY}

The enterprise we focus on is in the pharmacy industry locates in Northeast and has some certain regional specificities. As a group, it has three sub-companies locate in different provinces. Two of them are in Harbin, Heilongiiang province, the third one is in Hezhou, Guangxi Province. The ERP supplier they choose is INSPUR, one of the biggest domestic ERP suppliers. The system they choose is a group level product.

Start from ITP, things goes well through IT managerial support and IT innovation support. However, problems happened in rest processes. Being accustomed to their financial software, it's necessary to input existed data into new systems. The most difficult thing is to solve the problem that users always compare the new system's shortcomings to the old one's which influence their satisfaction and work efficiency. Due to the culture difference, people lived in northeastern tend to be more conservative and stubborn. Existed experiences block the progress of ERP project. 
Research on Implementing ERP in a Northeastern Enterprise Based on Information Orientation

Theory 255

Training and direct commands from superior are intensified simultaneously to prompt ERP implementation.

Table 2. Related ERP Behaviors to IMP\&IBV

\begin{tabular}{|c|c|c|}
\cline { 3 - 3 } \multicolumn{1}{c|}{} & Influence Factors \\
\hline \multirow{4}{*}{ IMP } & Sensing/Collection & ERP \\
\cline { 2 - 3 } & Organizing & InsidelOutside Environment \\
\cline { 2 - 3 } & Processing & ERP \\
\cline { 2 - 3 } & Maintaining & Rules \\
\cline { 2 - 3 } & Integrity & ERP \\
\hline IBV & Formality & ERP \\
\cline { 2 - 3 } & Control & BPR \\
\cline { 2 - 3 } & Transparency & Rules \\
\cline { 2 - 3 } & Sharing/ Proactiveness & \\
\hline
\end{tabular}

BPR is another field that encounters problems. Being a former state-owned enterprise, one of its sub-companies has many cockamamie and out of date business processes. Taking the approval of purchase capital as an example, after the approval of manager from purchase department, it should then be checked by manager account for production for right material and then be checked by financial manager for right amount, while material requirement plan is brought up by production department. We rearranged the process after the implementation by cutting off the double check of production manager.

There are problems in information collecting for IMP. For example, due to incomplete market economy, some suppliers don't afford value added tax invoice or change the title of invoice which hamper the account processing. The direct result is that the name in value added tax invoice doesn't coincide with the name in the purchase order, which confuses information collecting. Since it is impossible to control supplier, we recommend the purchase department request right invoice before signing the purchase contract. The availability of IT human resource of enterprise interferes with the information organizing during the ERP implementation process. Information department in this pharmacy enterprise is built up in a hurry and qualified employees are in a short. Problems can't be solved in time, sometime even cannot be treated kindly which hurt the interests of users from other departments. We intensify the training for the final users to increase their understanding to the ERP system and hand out more operational handbook on one hand; On the other hand, we picked out key nodes that must be paid full attention by information department.

As listed above, IBV concerns each movement of human being involved with information. While sharing is talked, we find that managers of each department prefer to keep information their own instead of sharing. One of the purchase managers even requests us to keep the name of supplier as a department secret, and not to share with other departments. Distributed channel managers also keep all of their information as secrets. Aimed at maximizing information's value, communicated with superior manager, they released a series rules to share these kind of information.

From the analysis above, it can be safely drawn that information itself should be taken seriously while doing ERP implementation. By dividing the process of 
implementation into ITP, IMP and IBV, ERP consultants and project managers can take more specific and pertinent measures.

\section{CONCLUSIONS}

Based on Information Orientation Theory, we suggest measures related to information during ERP implementation process. For example, when stubborn user kept on hanging around previous system, we suggest an intensification of vertical command. Employees' behavior of refusing share key information is exposed when IBV is considered.

Information orientation theory views information as its target. Starting from information technology, it mainly research about the management, behavior and values of information. As ERP implementation is concerned, integrating the information management with operation of ERP system affords an opportunity to manage information well.

Another side about information management is related to Competitive Intelligence (CI) and Counterintelligence system. In fact, the two aspects do have some common thing in their process which beyond this paper's discussion which will be our next research topic.

\section{REFERENCES}

1. N. Melone, A theoretical assessment of the user-satisfaction construct in information systems research, Management Science. Volume 36, Number 1, pp.76-91, (1990).

2. V. Venkatesh, M. Morris, G. Davis, and F. Davis, User acceptance of information technology: Toward a unified view, MIS Quarterly. Volume 27, Number 3, pp.425-478, (2003).

3. H.W. Barbara and A.T. Peter, A Theoretical Integration of User Satisfaction and Technology Acceptance, Information Systems Research. Volume 16, Number 1, pp.85102, (2005).

4. D.A. Marchand, Competing with information: A manager's guide to creating business value with information content (John Wiley and Sons: Chichester, England, 2000).

5. D.A. Marchand, W.J. Kettinger, and J.D. Rollins, Information orientation: People, technology and the bottom line, MIT Sloan Management Review. Volume 4, Number 41, pp.69-80, (2000).

6. D.A. Marchand, W.J. Kettinger, and J.D. Rollins, Information orientation: The new business performance metric (Oxford University Press: Oxford, Great Britain, 2001).

7. D.A. Marchand, W.J. Kettinger, and J.D. Rollins, Making the invisible visible: How companies win with the right information, people and IT (John Wiley and Sons: Chichester, England, 2001). 